\title{
Evaluation of Uncertainty in Determination Methods of Seawater pH Standard Material
}

\author{
Chaoying Shi", Hong Zhao, Xiaohui Zhang and Yan Luo \\ National Center of Ocean Standards and Metrology, Ministry of Natural Resources
}

\begin{abstract}
Seawater $\mathrm{pH}$ standard material is determined by potentiometric methods with hydrogen electrode silver / silver chloride electrode in nonliquid junction cell. As a standard material, uncertainty is an important quality parameter. The sources of the uncertainty of determination methods mainly include measurement repeatability and temperature, atmospheric pressure, electrode potential, chloride concentration and so on. According to the experimental data, the expanded uncertainty of the method is 0.004 . Finally, through in-depth analysis of the influence weight of each component, it is found that the quality control of the standard electrode potential, measurement repeatability and chloride ion concentration of the electrode in the ion system is the key to ensure the accuracy of the setting value, which provides a reliable guarantee for the replication of reference materials.
\end{abstract}

\section{Introduction}

Seawater $\mathrm{pH}$ is an important parameter to study seawater acidification and marine carbon cycle system. The four parameters of $\mathrm{pH}$, total alkalinity, partial pressure of carbon dioxide and dissolved inorganic carbon are important parameters of marine carbon cycle system. They are indispensable. The measurement accuracy requirements of each parameter in different research systems are different, for example, the accuracy of each component of carbonate system is required to be \pm 0.005 , the apparent constant of carbonate system requires its accuracy to be \pm 0.001 . So it is necessary and also important to control seawater $\mathrm{pH}$ accurately, which is required to be \pm 0.005 .

For the measurement of $\mathrm{pH}$ parameters, the ionic strength of the existing reference materials is 0.1 . For the samples with low ionic strength, the electrode potential is basically close to that of the reference materials, and a relatively constant result can be obtained. For seawater samples, the ionic strength is about 0.7. There is a liquid junction potential between the external reference solution of the reference electrode and the solution to be measured (existing reference materials and seawater samples). The liquid junction potential is different due to the difference between the reference materials and seawater samples. Therefore, the liquid junction potential difference is included in the determination of $\mathrm{pH}$ value of seawater samples by using existing reference materials, and the current liquid junction potential difference cannot be measured or calculated [1].

\footnotetext{
*Corresponding author: tenfly04@126.com
} 
In order to solve the problem of liquid to liquid potential difference in measuring seawater $\mathrm{pH}$, Hansson and many other researchers suggested that artificial seawater should be used to prepare reference materials [1,2,3], that is, neutral organic base trihydroxymethylaminomethane (hereinafter referred to as "Tris") should be prepared in artificial seawater with different salinities [2], tris (replaced by "B" in the chemical formula) should be used as buffer material, and the protonated form of $\mathrm{BH}+$ at $25{ }^{\circ} \mathrm{C}$ The pKa value of dissociation constant is 8.075 [4,5], which means that "Tris" buffer solution mixed with $\mathrm{B}$ and $\mathrm{BH}+$ is suitable for the measurement of $\mathrm{pH}$ value in the range of (7-9), which is called Hansson scale reference material. The ionic strength of the reference material is the same as that of seawater sample, which makes the liquid junction potential offset each other. Therefore, the determination result is accurate and reproducible, which is suitable for the analysis of various components of carbonate system. In order to distinguish easily, the commonly used $\mathrm{pH}$ buffer solution (including potassium hydrogen phthalate, mixed phosphate and borax) is called NBS standard material. The buffer solution is easy to operate and suitable for the analysis of total carbonate. The two kinds of standards have their own characteristics, and there is a certain market demand to choose different standards in different research systems.

In order to measure the $\mathrm{pH}$ of seawater more accurately, we established the platinum hydrogen electrode silver / silver chloride electrode non-liquid junction cells to determine the value of seawater $\mathrm{pH}[6]$, which is similar to the Hansson's measurement. Different from existing seawater $\mathrm{pH}$ measurement methods, $\mathrm{pH}$ is determined without liquid junction, while the influence of sulphate ion in seawater and salinity is also considered here. This method is an absolute measurement method established according to $\mathrm{pH}$ international recommendation, and is also the method with the highest $\mathrm{pH}$ measurement accuracy at present. As a standard material, uncertainty is an important quality parameter. Taking salinity 35 as an example, this paper analyzes the influencing factors in the process of setting value one by one, and calculates them respectively according to the setting value data, and finally obtains the expanded uncertainty of the method of setting value of seawater $\mathrm{pH}$ reference material.

\section{Determination principle of seawater $\mathrm{pH}$ reference material}

The reaction of seawater $\mathrm{pH}$ reference material in Harned cell is as follows:

$$
\mathrm{Pt}(\mathrm{s})\left|\mathrm{H}_{2}\left(\mathrm{~g}, p^{0}\right)\right| \mathrm{BH}^{+} \text {and } \mathrm{B} \text { in the seawater }|\mathrm{AgCl}(\mathrm{s})| \mathrm{Ag}(\mathrm{s}) \mid \mathrm{Pt}(\mathrm{s})
$$

cell potential:

$$
E=E^{\circ}-\left(\frac{R T}{F}\right) \ln \left\{\frac{m\left(\mathrm{H}^{+}\right) m\left(\mathrm{Cl}^{-}\right)}{\left(m^{\circ}\right)^{2}}\right\}-\left(\frac{2 R T}{F}\right) \ln \gamma_{ \pm}(\mathrm{HCl})
$$

Where $\mathrm{m} 0=1 \mathrm{~mol} / \mathrm{kg}$.

$$
\begin{aligned}
& E_{m}^{*}=E^{0}-\frac{2 R T}{F} \ln \gamma_{ \pm}^{\mathrm{tr}}(\mathbf{H C l}) \\
& \text { If }{ }^{*} \text {, then } \\
& E_{m}^{*}=E^{0}-\frac{2 R T}{F} \ln \gamma_{ \pm}^{\mathrm{tr}}(\mathrm{HCl})=\lim _{m(\mathrm{HCl}) \rightarrow 0}\left[E+\frac{R T}{F} \ln \frac{m\left(\mathrm{H}^{+}\right) m\left(\mathrm{Cl}^{-}\right)}{\left(m^{0}\right)^{2}}\right]
\end{aligned}
$$

Where it is defined as the standard electrode potential of silver / silver chloride electrode in the ionic system. By adding different concentrations of $\mathrm{HCl}$ into the artificial 
seawater with a certain salinity, the battery potential can be measured, which can be extrapolated to the battery potential (at different salinities and temperatures) when the concentration of $\mathrm{HCl}$ is 0 . The median value in this paper is obtained from reference data [7].

Due to the presence of sulphate ion in seawater, the following reactions of hydrogen ion also occur:

$$
\mathrm{HSO}_{4}^{-}(\mathrm{aq})=\mathrm{H}^{+}(\mathrm{aq})+\mathrm{SO}_{4}^{2-}(\mathrm{aq})
$$

If we use the dissociation constant expressed by molar concentration, we can get the dissociation constant:

$$
K_{m}^{0}\left(\mathrm{HSO}_{4}^{-}\right)=\lim _{m\left(\mathrm{SO}_{4}^{2-}\right) \rightarrow \rightarrow^{\mathrm{T}} m\left(\mathrm{SO}_{4}^{2-}\right)} Q_{m}\left(\mathrm{HSO}_{4}^{-}\right)=\lim _{m\left(\mathrm{SO}_{4}^{2-}\right) \rightarrow \rightarrow^{\mathrm{T}} m\left(\mathrm{SO}_{4}^{2-}\right)} \frac{m\left(\mathrm{H}^{+}\right) \cdot m\left(\mathrm{SO}_{4}^{2-}\right)}{m\left(\mathrm{HSO}_{4}^{-}\right)}
$$

Substituting $E_{m}^{*}$ and $K_{m}^{0}\left(\mathrm{HSO}_{4}^{-}\right)$into the formula of cell (I):

$$
E=E_{m}^{*}-\left(\frac{R T}{F}\right) \ln \left\{\frac{m^{*}\left(\mathrm{H}^{+}\right) m\left(\mathrm{Cl}^{-}\right)}{\left(m^{\circ}\right)^{2}}\right\}-\left(\frac{2 R T}{F}\right) \ln \left\{\frac{\gamma_{ \pm}(\mathrm{HCl})}{\gamma_{ \pm}^{\mathrm{tr}}(\mathrm{HCl})}\right\}
$$

If the ionic activity term is ignored $-\left(\frac{2 R T}{F}\right) \ln \left\{\frac{\gamma_{ \pm}(\mathrm{HCl})}{\gamma_{ \pm}^{\text {tr }}(\mathrm{HCl})}\right\}$, in other words $\left\{\frac{\gamma_{ \pm}(\mathrm{HCl})}{\gamma_{ \pm}^{\text {tr }}(\mathrm{HCl})}\right\}_{=1, \text { then: }} \mathrm{pH}_{m}=-\log \left\{\frac{m^{*}\left(\mathrm{H}^{+}\right)}{m^{\circ}}\right\}=\frac{E-E_{m}^{*}}{R T \ln 10 / F}+\log \left\{\frac{m\left(\mathrm{Cl}^{-}\right)}{m^{\circ}}\right\}$

This $\mathrm{pH}_{\mathrm{m}}$ is the $\mathrm{pH}$ scale of total hydrogen ion concentration [8]. In the formula, $R$ is the molar constant of gas and $F$ is the Faraday constant. In marine chemistry, "concentration" is usually expressed as content (mole / $\mathrm{kg}$ seawater), while in the physical chemistry of aqueous solution, molar concentration (mole $/ \mathrm{kg}$ water) is usually used. When $\mathrm{PH}_{\mathrm{T}}$ is defined as the $\mathrm{pH}$ scale of total hydrogen ion concentration (mole / $\mathrm{kg}$ seawater) [8], we can get:

$$
\mathrm{pH}_{\mathrm{T}}=\mathrm{pH}_{\mathrm{m}}-\log (1-0.00106 \mathrm{~S})
$$

\section{Uncertainty analysis of determination methods}

The sources of uncertainty in the determination methods of seawater $\mathrm{pH}$ reference materials [9] mainly include:

(1) Class A uncertainty component from measurement repeatability in determination process;

(2) Class B uncertainty component from temperature, atmospheric pressure, electrode potential, chloride concentration and other factors.

\subsection{Uncertainty component class $A$ uncertainty $u_{A}$}

The component of class A uncertainty introduced in the determination process of mainly comes from the measurement repeatability. The standard deviation of $\mathrm{pH}_{\mathrm{T}}$ measured at each 
temperature point is within 0.0015 [6]. If the maximum value of $\mathrm{pH}_{\mathrm{T}}$ standard deviation is taken as the repeatability of the setting value result, $s=0.0015$, the component of uncertainty from the measurement repeatability is less than $u_{\mathrm{A}}=\frac{s}{\sqrt{n}}=\frac{0.0015}{\sqrt{5}}=0.00067$.

\subsection{Uncertainty component class B uncertainty}

The class B uncertainty component introduced in the process of setting value mainly comes from temperature, electrode potential and chloride ion concentration. According to the law of uncertainty propagation, the mathematical model of seawater $\mathrm{pH}$ reference material was established:

$$
\mathrm{pH}_{\mathrm{T}}=\frac{E-E_{m}^{*}}{R T \ln 10 / F}+\log \left\{\frac{m\left(\mathrm{Cl}^{-}\right)}{m^{\circ}}\right\}-\log (1-0.00106 S)
$$

Partial differentiation is made for each parameter value, and the class B standard uncertainty component introduced in the process of setting value is calculated according to the following formula:

$u_{B}=\sqrt{\left(\frac{F}{R \times T \times \ln 10}\right)^{2} \times u^{2}(E)+\left(\frac{-F}{R \times T \times \ln 10}\right)^{2} \times u^{2}\left(E_{m}^{*}\right)+\left(\frac{-F \times\left(E-E_{m}^{*}\right)}{R \times T^{2} \times \ln 10}\right)^{2} \times u^{2}(T)+\left(\frac{1}{m\left(C l^{-}\right) \times \ln 10}\right)^{2} \times u^{2}(m)+\left(\frac{-0.00106}{(1-0.00106 S) \times \ln 10}\right)^{2} \times u^{2}(S)}$

Where $u(E)$ means standard uncertainty component introduced by electrode potential;

$\mathrm{u}\left(\mathrm{E}_{\mathrm{m}}^{*}\right)$ means the standard uncertainty component introduced by the standard electrode potential;

$\mathrm{u}(\mathrm{T})$ means uncertainty component of temperature measurement;

$\mathrm{u}(\mathrm{m})$ means standard uncertainty component introduced by chloride ion concentration;

$\mathrm{u}(\mathrm{S})$ means the uncertainty component of salinity measurement.

\subsubsection{Standard uncertainty component introduced by electrode potential $u(E)$}

According to the calibration certificate, the maximum relative uncertainty of $8508 \mathrm{a}$ DMM in the range of $2 \mathrm{~V}$ is $3.5 \times 10^{-6}, k=2$, and the uncertainty component introduced by electrode potential is $u(E)=3.5 \times 10^{-6} \times 0.75 / 2=1.4 \times 10^{-6} \mathrm{~V}$.

\subsubsection{The standard uncertainty component introduced by the standard electrode potential $u\left(\boldsymbol{E}_{\boldsymbol{m}}^{*}\right)$}

According to reference [7], the accuracy of $E_{\mathrm{m}}{ }^{*}$ is $0.1 \mathrm{mv}$ after it is corrected to $0.22240 \mathrm{v}$. The theoretical value is used in this paper, but the difference between the standard potential of silver chloride electrode in pure water and the standard electrode potential is obtained by measuring the hydrochloric acid solution of $0.01 \mathrm{~mol} / \mathrm{L}$ determined by Coulomb apparatus before each measurement. The difference between the measured potential of $\mathrm{AgCl}$ standard electrode and the theoretical value at each temperature point is less than $0.13 \mathrm{mV}$. According to the uniform distribution, the inclusion factor is $k=\sqrt{3}$, which is the standard uncertainty component introduced by the electrode $E_{\mathrm{m}}{ }^{*}$ in the ion $\operatorname{system:} u\left(E_{m}^{*}\right)=$ $\sqrt{0.1^{2}+0.13^{2}} / \sqrt{3} / 1000=9.5 \times 10^{-5} \mathrm{~V}$.

\subsubsection{Uncertainty component of temperature measurement $u(T)$}

The uncertainty components of temperature measurement include the standard uncertainty component $u_{1}(T)$ of standard platinum resistance thermometer, the standard uncertainty 
component $u_{2}(T)$ of temperature measurement bridge and the uncertainty component $u_{3}(T)$ of constant temperature water bath temperature. The standard uncertainty component introduced by standard platinum resistance thermometer is $u_{1}(T)=0.001 / 3=3.3 \times 10^{-4}{ }^{\circ} \mathrm{C}$. The standard uncertainty component of temperature measurement bridge is $u_{2}(T)=3.3 \times 10^{-5 \circ} \mathrm{C}$. The uncertainty component $u_{3}(T)$ of constant temperature water bath temperature is $u_{3}(T)=\sqrt{\left(\frac{0.001}{\sqrt{3}}\right)^{2}+\left(\frac{0.001}{\sqrt{3}}\right)^{2}}=0.00082^{\circ} \mathrm{C}$.

The above three components are combined to obtain the uncertainty component of temperature measurement: $u(T)=0.0009^{\circ} \mathrm{C}$.

\subsection{4 standard uncertainty component introduced by chloride ion concentration $u(m)$}

The uncertainty component of chloride concentration comes from the maximum allowable error of electronic balance, the repeatability of weighing results and the uncertainty of nominal value of purity of reference materials, whose uncertainty components are in the Table 1. The chloride concentration is calculated as follows.

$$
m\left(C l^{-}\right)=\frac{m_{1}+m_{2}+2 m_{3}+2 m_{4}+m_{5}}{m_{\text {总 }}}
$$

Where $\mathrm{m} 1, \mathrm{~m} 2, \mathrm{~m} 3, \mathrm{~m} 4, \mathrm{~m} 5$ respectively mean the quality of $\mathrm{NaCl}, \mathrm{KCl}, \mathrm{MgCl} 2 \cdot 6 \mathrm{H} 2 \mathrm{O}, \mathrm{CaCl} 2$ and tris $\bullet \mathrm{HCl}$, and $m_{\mathrm{T}}$ means Total mass of prepared solution.

According to the law of uncertainty propagation, the uncertainty component of chloride ion concentration can be obtained by synthesizing the uncertainty components of these substances.

$$
\begin{aligned}
u(m) & = \\
\sqrt{\left(\frac{1}{m_{\mathrm{T}}}\right)^{2}} \times u^{2}\left(m_{1}\right)+\left(\frac{1}{m_{\mathrm{T}}}\right)^{2} \times u^{2}\left(m_{2}\right)+\left(\frac{2}{m_{\mathrm{T}}}\right)^{2} \times u^{2}\left(m_{3}\right)+\left(\frac{2}{m_{\mathrm{T}}}\right)^{2} \times u^{2}\left(m_{4}\right)+\left(\frac{1}{m_{\mathrm{T}}}\right)^{2} \times u^{2}\left(m_{5}\right)+\left(\frac{m_{1}+m_{2}+2 m_{3}+2 m_{4}}{m_{\mathrm{T}}^{2}}\right)^{2} \times u^{2}\left(m_{\mathrm{T}}\right) & \\
& =3.0 \times 10^{-5}(\mathrm{~g})
\end{aligned}
$$

Table 1. Uncertainty components of each substance

\begin{tabular}{ccccc}
\hline substance & $\begin{array}{c}\text { the maximum } \\
\text { allowable error } \\
\text { of electronic } \\
\text { balance }(\mathrm{g})\end{array}$ & $\begin{array}{c}\text { the uncertainty } \\
\text { of nominal value } \\
\text { of purity of } \\
\text { reference } \\
\text { materials }(\mathrm{g})\end{array}$ & $\begin{array}{c}\text { the repeatability of } \\
\text { weighing results }(\mathrm{g})\end{array}$ & $\begin{array}{c}\text { the uncertainty } \\
\text { component of } \\
\text { chloride ion } \\
\text { concentration }(\mathrm{g})\end{array}$ \\
\hline $\mathrm{NaCl}$ & 0.00173 & 0.07817 & 0.00016 & 0.07819 \\
$\mathrm{KCl}$ & 0.00116 & 0.00272 & $3.35 \times 10^{-5}$ & 0.00296 \\
$\mathrm{MgCl}_{2} \bullet 6 \mathrm{H}_{2} \mathrm{O}$ & 0.00173 & 0.22478 & 0.00035 & 0.17983 \\
$\mathrm{CaCl}_{2}$ & 0.00116 & 0.04116 & $5.77 \times 10^{-5}$ & 0.04118 \\
tris $\bullet \mathrm{HCl}$ & 0.00173 & 0.21743 & $5.77 \times 10^{-5}$ & 0.21743 \\
Total solution & 0.577 & - & 0.03334 & 0.5783 \\
\hline
\end{tabular}

\subsubsection{The uncertainty component of salinity measurement $u(S)$}

The 8400B Laboratory Salinometer is used in salinity measurement. According to the calibration certificate, the expanded uncertainty of $8400 \mathrm{~B}$ Laboratory Salinometer in the 
range of salinity $(2 \sim 35)$ is $1.2 \times 10-3$, then the uncertainty component of salinity measurement $\mathrm{u}(\mathrm{S})=1.2 \times 10-3 / 2=6.0 \times 10-4$.

\subsection{Combined uncertainty $\mathrm{u}$}

Table 2. Uncertainty components in the determination process

\begin{tabular}{ccc}
\hline sources & uncertainty components & Sensitivity coefficient \\
\hline Measurement repeatability $u_{\mathrm{A}}$ & 0.00067 & $c_{1}=1$ \\
Electrode potential $u(E)$ & $1.4 \times 10^{-5}$ & $c_{2}=\frac{F}{R \times T \times \ln 10}$ \\
Standard electrode potential of electrode & $9.5 \times 10^{-5}$ & $c_{3}=\frac{-F}{R \times T \times \ln 10}$ \\
$u\left(E_{m}^{*}\right)$ & 0.0009 & $c_{4}=\frac{-F \times\left(E-E_{m}^{*}\right)}{R \times T^{2} \times \ln 10}$ \\
Temperature $u(T)$ & $3.0 \times 10^{-5}$ & $c_{5}=0.76504$ \\
Chloride concentration $u(m)$ & 0.0006 & $c_{6}=4.8 \times 10^{-4}$ \\
Salinity $u(S)$ &
\end{tabular}

Table 3. Sensitivity coefficients $\mathrm{C} 2, \mathrm{C} 3$ and $\mathrm{C} 4$ at different temperatures and the uncertainty

\begin{tabular}{ccccc}
\hline Temperature $\left({ }^{\circ} \mathrm{C}\right)$ & $c_{2}$ & $c_{3}$ & $c_{4}$ & Combined uncertainty $u$ \\
\hline 10 & 17.79895 & -17.79895 & 0.03112 & 0.0018 \\
15 & 17.49010 & -17.49010 & 0.03000 & 0.0018 \\
20 & 17.19179 & -17.19179 & 0.02893 & 0.0018 \\
25 & 16.90348 & -16.90348 & 0.02791 & 0.0018 \\
30 & 16.62468 & -16.62468 & 0.02694 & 0.0017 \\
35 & 16.35493 & -16.35493 & 0.02601 & 0.0017 \\
\hline
\end{tabular}

There are the list of uncertainty components in the process of setting value in Table 2 , and the uncertainty of setting value results of each temperature by substituting these components into formula (9) in Table 3 . We can see although the sensitivity coefficients $\mathrm{c} 2$, $\mathrm{c} 3$ and $\mathrm{c} 4$ are related to the temperature, the electrode potentials corresponding to different temperatures are also different, and the uncertainty of the final calculation of the fixed value results at different temperature points is basically the same, so the combined uncertainty of the fixed value method can be obtained as $\mathrm{u}=0.0018$.

\subsection{Expanded uncertainty U}

Taking the factor $\mathrm{k}=2$, the expanded uncertainty of the determination method of seawater $\mathrm{pH}$ reference material is $\mathrm{U}=2 \times \mathrm{u}=0.004$.

\section{Uncertainty component analysis and quality improvement}

Combined with the uncertainty components in Table 2 and the sensitivity factor analysis in Table 3, the largest component in the process of setting value comes from the uncertainty component $U$ (E) introduced by the standard electrode potential of the electrode in the ion system $\mathrm{u}\left(\mathrm{E}_{\mathrm{m}}^{*}\right)$. The standard electrode potential of the electrode in the ion system is caused by the deviation of the platinum hydrogen electrode silver / silver chloride electrode. Therefore, it is very important to select the appropriate platinum hydrogen electrode silver / silver chloride electrode, which directly affects the determination result of seawater $\mathrm{pH}$ standard material. It should be noted that although the accuracy of DMM for measuring 
electrode potential is sufficient, it is still affected by the electrode itself, resulting in the influence of uncertainty component introduced by measurement repeatability, which is second only to the standard electrode potential $\mathrm{u}\left(\mathrm{E}_{\mathrm{m}}^{*}\right)$.In addition, only sodium chloride, potassium chloride and sodium sulfate have high purity certified reference materials (purity is more than $99.95 \%$ ) in various salt chemical reagents for preparing seawater $\mathrm{pH}$ certified reference materials. In addition, calcium chloride and magnesium chloride have no purity certified reference materials and are easy to absorb moisture in the weighing process, which not only increases the difficulty of preparation, but also makes the introduction of chloride ion concentration calculated by weighing more difficult The influence of uncertainty component is great. The influence of other factors is at least one order of magnitude smaller than these three factors. Therefore, the quality control of these three factors is the key to ensure the accuracy of setting value.

\section{Conclusion}

The uncertainty of the determination method of seawater $\mathrm{pH}$ reference material is analyzed and studied. By evaluating the uncertainty components introduced by measurement repeatability, temperature, atmospheric pressure, electrode potential, chloride concentration and other factors, the expanded uncertainty of seawater $\mathrm{pH}$ reference material is 0.004 . Finally, through in-depth analysis of the influence weight of each component, it is found that the quality control of the standard electrode potential, measurement repeatability and chloride ion concentration of the electrode in the ion system is the key to ensure the accuracy of the setting value, which provides a reliable guarantee for the replication of reference materials.

\section{References}

[1] Ingemar Hansson. A new set of $\mathrm{pH}$-scales and standard buffers for sea water. Deep Sea Research and Oceanographic Abstracts. 1973, 20(5):479-491.

[2] Dickson, A.G. and Riley, J.P.. The estimation of acid dissociation constants in seawater media from potentiometric titrations with strong base.I. The ionic product of water $\left(\mathrm{K}_{\mathrm{w}}\right)$. Marine Chemistry, 1979 , 7:89-99.

[3] DelValls T.A., Dickson A.G..The pH of buffers based on 2-amino-2-hydroxymethyl1,3-propanediol(tris) in synthetic sea water. Deep-Sea Research.1998,45(8):1541-1554.

[4] Dickson A.G. The measurement of seawater pH. Marine Chemistry,1993,44:131-142.

[5] Waters Jason F.,"Measurement of Seawater pH: A Theoretical and Analytical Investigation". Open Access Dissertations,2012:908.

[6] Chaoying Shi, Hongyu Xiu, Xiaohui Zhang, Yan Luo, Hong Zhao. Research on reference materials for measuring seawater $\mathrm{pH}$ by Potentiometric method. Proceedings of academic exchange meeting on meteorological, hydrological and marine instruments in February 2019. 68-74.

[7] Dickson, A.G.. Standard potential of the reaction: $\operatorname{AgCl}(s)+\frac{1}{2} H_{2}(g)=\operatorname{Ag}(s)+$ $\mathrm{HCl}(\mathrm{aq})$, and the standard acidity constant of the ion $\mathrm{HSO}_{4}^{-}$in synthetic sea water from 275.15 to $318.15 \mathrm{~K}$. Chem. Themodyn. ,1990,22:113-127.

[8] Dickson A.G. pH buffers for sea water media based on the total hydrogen ion concentration scale. Deep-Sea Research.1993,40:107-118.

[9] General principles and statistical principles of certified reference materials [S] (jjf1343-2012), 2012 